\title{
CORONARY ARTERY BYPASS GRAFIING IN PATIENTS WITH PREVIOUS MEDIASTINAL RADIATION THERAPY
}

Nobuhiro Handa, MD

Christopher G. A. McGregor, MB, FRCS

Gordon K. Danielson, MD

Thomas A. Orszulak, MD

Charles J. Mullany, MB, MS

Richard C. Daly, MD

Joseph A. Dearani, MD

Betty J. Anderson, RN

Francisco J. Puga, MD
Objectives: Our objectives were to characterize the outcome of coronary artery bypass grafting in patients with previous mediastinal radiation therapy and to identify special features of this condition that relate to surgical management. Patients and methods: We conducted a retrospective review of 47 patients ( 28 women, 19 men) with a mean age of $63.5 \pm 12.8$ years (range 31.0-82.9 years) from 1976 through December 1996 undergoing coronary artery bypass graft after mediastinal radiation therapy. Results: The mean interval between mediastinal radiation therapy and coronary artery bypass grafting was 15.1 \pm 9.8 years (range 1.1-37.8 years). In the 44 patients with isolated coronary surgery, operative mortality was 3 patients $(6.8 \%)$. Sternal wound infection occurred in 3 patients $(6.8 \%)$. Actuarial survival at 1 and 5 years was $87.2 \% \pm 4.9 \%$ and $71.6 \% \pm 7.1 \%$, respectively. Total follow-up was 293.7 patient-years (mean 6.2 \pm 5.1 years). There were 17 late deaths (malignancy, $n=7$; heart failure, $n=6$; stroke, $n=1$; other noncardiac causes, $n=2$; and sudden death, $n=1$ ). Twelve of 43 discharged patients had the development of valvular disease demonstrated by follow-up echocardiography. Conclusions: The early results of coronary artery bypass grafting for the treatment of ischemic heart disease after mediastinal radiation therapy are good. Late survival, however, is limited by malignancy, either recurrent or new, and the development of heart failure. Inasmuch as 25 other patients after radiation therapy required concomitant valve surgery and 12 of $43(28 \%)$ discharged patients had later development of valvular disease, with 2 requiring reoperation, careful assessment of any valvular lesion is important during the initial coronary artery bypass grafting. Careful follow-up, including regular echocardiographic screening, is recommended in this patient population. (J Thorac Cardiovasc Surg 1999;117:1136-43)
A $\mathrm{n}$ increasing number of patients with malignant neoplasm treated with irradiation survive long term after treatment. In particular, there are an increasing number of long-term survivors of Hodgkin's disease and breast cancer who have undergone mediastinal radiation thera-

From the Division of Thoracic and Cardiovascular Surgery, Mayo Clinic and Mayo Foundation, Rochester, Minn.

Read at the Seventy-eighth Annual Meeting of The American Association for Thoracic Surgery, Boston, Mass, May 3-6, 1998.

Received for publication May 8, 1998; revisions requested June 1, 1998; revisions received Feb 5, 1999; accepted for publication Feb 19, 1999

Address for reprints: Christopher G. A. McGregor, MB, FRCS, Mayo Clinic and Foundation, 6-716 Mary Brigh D, Saint Marys Hospital, Rochester, MN 55905.

Copyright (C) 1999 by Mosby, Inc.

$0022-5223 / 99 \$ 8.00+0 \quad \mathbf{1 2 / 6 / 9 8 0 6 7}$ py. ${ }^{1-4}$ Heart disease has become a major cause of late morbidity and mortality in these groups of patients. ${ }^{5-8}$ The effects of mediastinal radiation therapy on the heart include pericardial disease, myocardial fibrosis, valvular heart disease, coronary artery disease, and conduction disturbances. ${ }^{9}$ A relatively small number of cases of coronary artery bypass grafting $(\mathrm{CABG})$ in patients with previous mediastinal radiation therapy have been reported. ${ }^{10-15}$ This is a single-center study of coronary revascularization in patients with previous mediastinal radiation therapy over a 21-year period to establish early and late outcomes and identify special features of this disease as they relate to surgical management.

\section{Patients and methods}

At the Mayo Clinic, from January 1976 through December 1996, patients who had a CABG procedure were matched 
Table I. Cardiac surgical procedures performed in 72 patients after mediastinal radiation therapy

\begin{tabular}{lcc}
\hline & $\begin{array}{c}\text { Surgical } \\
\text { procedures }\end{array}$ & No. \\
\hline Study group & 44 & 47 \\
$\quad$ CABG & 2 & \\
CABG + pericardiectomy & 1 & \\
CABG + LV aneurysmectomy & 19 & 25 \\
Excluded patients & 6 & \\
CABG + single valve surgery & & 72 \\
$\quad$ CABG + multiple valve surgery & & \\
Total
\end{tabular}

$C A B G$, Coronary artery bypass grafting; $L V$, left ventricular.

with patients with malignant neoplasms who might have been treated by mediastinal radiation therapy. Those malignant neoplasms include breast cancer, lymphoma, lung cancer, esophageal cancer, thymoma, and germ cell tumors of the mediastinum. ${ }^{16} \mathrm{~A}$ total of 72 patients were identified. Cardiac surgical procedures performed are detailed in Table I. Twenty-five patients who had combined CABG and valve surgery were excluded from this analysis. Accordingly, 47 patients were evaluated in this study. A retrospective review of operative notes, anesthesia records, clinical case histories, and laboratory investigations including electrocardiography, echocardiography, cardiac catheterization data and radiation oncology records was done. Follow-up data were collected by clinic records of subsequent outpatient visits and correspondence with patients and referring physicians, focusing on functional and echocardiographic status as well as the state of the malignant disease. A total of 264 clinical, hemodynamic, electrocardiographic, and echocardiographic variables in each patient were entered into a computerized database and analyzed. More than 6 months' follow-up data were completed in all patients. Demographic and cardiac data of the 47 patients in this study are detailed in Table II. Of note, $60 \%$ were female and $32 \%$ of patients had left main disease.

Preoperative risk factors and comorbidities are detailed in Table III. Of note, esophageal stricture and pulmonary fibrosis induced by mediastinal radiation therapy were observed in $3(6 \%)$ and $11(23 \%)$ patients, respectively. Thirty-two percent of the patients had pulmonary parenchymal disease, either chronic obstructive pulmonary disease or pulmonary fibrosis (or a combination of the two). Carotid disease, defined as more than $50 \%$ stenosis, documented by carotid ultrasound or angiography, was present in 11 patients (23\%). The indications for mediastinal radiation therapy were breast cancer in 26 patients (55\%), Hodgkin's lymphoma in 10 patients (21\%), non-Hodgkin's lymphoma in 8 patients (17\%), and lung cancer in 3 patients $(6 \%)$. Radiation dosage was available in 26 of 47 patients (55\%). The mean dose of radiation was $57.3 \pm 17.7 \mathrm{~Gy}$. The interval between the end of radiation therapy and CABG was $15.1 \pm 9.8$ years (range 1.1 37.8 years). Nine patients had chemotherapy concomitant with mediastinal radiation therapy.
Table II. Demographic and cardiac data (47 patients)

\begin{tabular}{lcr}
\hline Variable & No. $(n=47)$ & $\%$ \\
\hline Male sex & 19 & 40 \\
Age (y) & $63.5 \pm 12.8$ & \\
NYHA class III or IV & 43 & 92 \\
History of stroke & 3 & 6 \\
Previous heart surgery & 1 & 2 \\
History of MI & 27 & 57 \\
History of PTCA & 7 & 15 \\
History of arrhythmia & 5 & 10 \\
One-vessel disease & 3 & 6 \\
Two-vessel disease & 12 & 26 \\
Three-vessel disease & 32 & 68 \\
Left main disease & 15 & 32 \\
\hline
\end{tabular}

NYHA, New York Heart Association; $M I$, myocardial infarction; PTCA, percutaneous transluminal coronary angioplasty.

Table III. Preoperative risk factors for coronary artery disease and comorbidities

\begin{tabular}{lcr}
\hline Variable & No. $(n=47)$ & $\%$ \\
\hline Risk factors & & \\
$\quad$ Smoking history & 15 & 32 \\
Hypertension & 22 & 47 \\
Hyperlipidemia & 15 & 32 \\
Diabetes mellitus & 14 & 30 \\
Family history & 16 & 34 \\
Comorbidity & & \\
$\quad$ Peripheral vascular disease & 8 & 17 \\
Carotid disease & 11 & 23 \\
Esophageal stricture & 3 & 6 \\
Pulmonary parenchymal disease & 15 & 32 \\
$\quad$ COPD & 4 & \\
Pulmonary fibrosis & 3 & \\
$\quad$ Both & 8 & \\
\hline
\end{tabular}

COPD, Chronic obstructive pulmonary disease.

Other cardiac lesions were assessed by either cardiac catheterization or echocardiography. Three of the 47 patients with moderate mitral regurgitation and 1 patient with moderate tricuspid regurgitation underwent $\mathrm{CABG}$ alone. No other patient had significant aortic, mitral, or tricuspid valve disease. The mean preoperative ejection fraction was $54.5 \% \pm 12.4 \%$.

Statistical methods. Survival, survival free of cardiac events, and reoperation were estimated as a function of time since surgery by means of the Kaplan-Meier method. Survival curves were compared by means of the log-rank test. Patient characteristics between groups were compared by means of $\chi^{2}$ tests or Fisher's exact tests for nominal variables, with 2-sample $t$ tests or Wilcoxon rank-sum tests for continuous variables and with Wilcoxon rank-sum tests for ordinal variables.

\section{Results}

The number of CABG procedures after mediastinal radiation therapy has increased over time at our institu- 


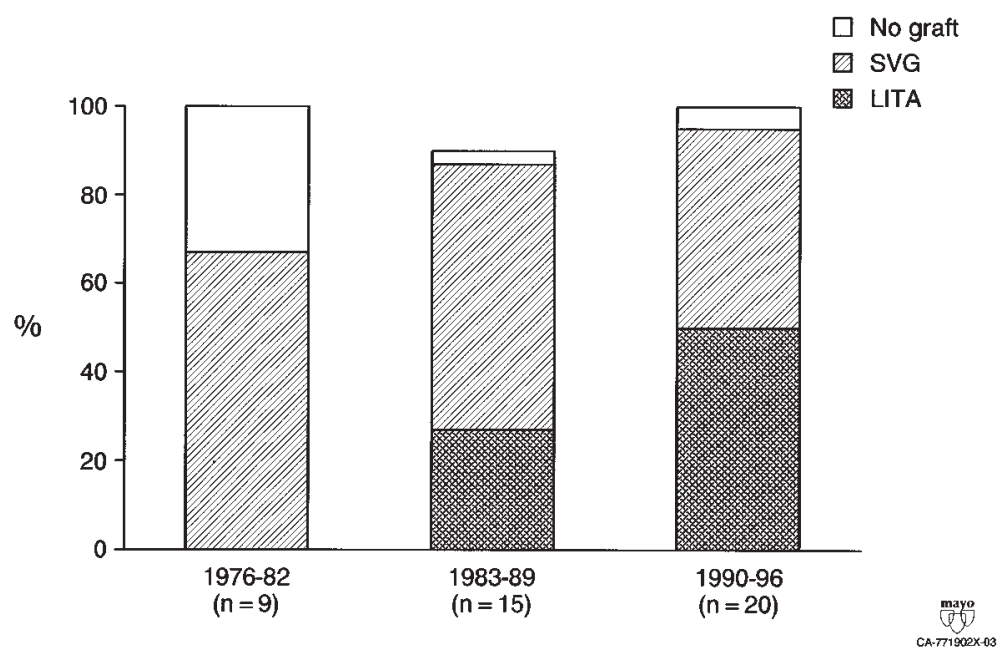

Fig 1. The relative percentages of patients receiving a saphenous vein graft ( $S V G)$, a left internal thoracic artery (LITA) graft, or no graft to the LAD over 3 time frames.

Table IV. Surgical procedures

\begin{tabular}{lcr}
\hline Variable & No. $(n=47)$ & $\%$ \\
\hline Graft to LAD & & 30 \\
$\quad$ LITA & 14 & 55 \\
SVG & 26 & 2 \\
LITA and SVG & 1 & 13 \\
No graft to LAD & 6 & \\
CABG + coronary endarterectomy & 2 & \\
CABG + pericardiectomy & 2 & \\
CABG + LV aneurysmectomy & 1 & \\
No. of distal anastomoses & $2.9 \pm 0.9$ & \\
CPB time (min) & $99.6 \pm 34.9$ & \\
Aortic crossclamp time (min) & $50.9 \pm 20.4$ &
\end{tabular}

$L A D$, Left anterior descending; LITA, left internal thoracic artery; SVG, saphenous vein graft; $C A B G$, coronary artery bypass graft; $L V$, left ventricular; $C P B$, cardiopulmonary bypass.

tion ( 9 cases from 1976 to 1982,15 cases from 1983 to 1989, and 20 cases from 1990 to 1996). The surgical procedures are detailed in Table IV. The mean number of distal anastomoses was $2.9 \pm 0.9$. Three patients had procedures in addition to CABG: coronary endarterectomy $(n=2)$, pericardiectomy $(n=2)$, and left ventricular aneurysmectomy $(\mathrm{n}=1)$. One patient had minimally invasive $\mathrm{CABG}$ without cardiopulmonary bypass. Of note, the left internal thoracic artery (LITA) was used to graft the left anterior descending (LAD) artery in $32 \%$ of patients. Use of the LITA graft was broken down into 3 time periods according to the year of operation, and the frequency increased over the period of the study (Fig 1). In the most recent time period (1990-1996) the LITA was used to graft the LAD in
Table V. Perioperative mortality and morbidity

\begin{tabular}{lcc}
\hline Variable & No. $(n=47)$ & $\%$ \\
\hline Mortality (overall) & 4 & 8.5 \\
Mortality (CABG alone) $(\mathrm{n}=44)$ & 3 & 6.8 \\
Mediastinal re-exploration for bleeding & 2 & 4.3 \\
Prolonged ventilation $(>72 \mathrm{~h})$ & 4 & 8.5 \\
Use of IABP & 2 & 4.3 \\
Deep sternal infection & 3 & 6.8 \\
Sternal malunion & 1 & 2.1 \\
Renal insufficiency (creatine $>3.0 \mathrm{mg} / \mathrm{dL})$ & 1 & 2.1 \\
GI perforation & 1 & 2.1 \\
Infective endocarditis & 1 & 2.1 \\
ICU stay (days) (mean) & $2.35 \pm 1.3$ & \\
Hospital stay (days) (mean) & $11.5 \pm 11.3$ & \\
\hline
\end{tabular}

CABG, Coronary artery bypass graft; IABP, intra-aortic balloon pump; $G I$, gastrointestinal; $I C U$, intensive care unit.

$50 \%$ of patients. In $20 \%$ of cases in which the saphenous vein was used as a conduit to the LAD, the surgeon commented on the operation report that the LITA was involved in areas of mediastinal fibrosis. Perioperative mortality and morbidity are shown in Table V. Overall perioperative mortality was 4 patients (8.5\%). One of these 4 patients had CABG plus pericardiectomy. This patient was a 74-year-old man with diabetes in whom mediastinitis developed; he subsequently died of infective endocarditis on postoperative day 15. Operative mortality, therefore, for the patients with isolated CABG $(\mathrm{n}=44)$ was 3 patients $(6.8 \%)$. The first of these 3 patients, a 54-year-old woman, was discharged on postoperative day 8 and died of an apparent myocardial infarction 6 days later. The second 


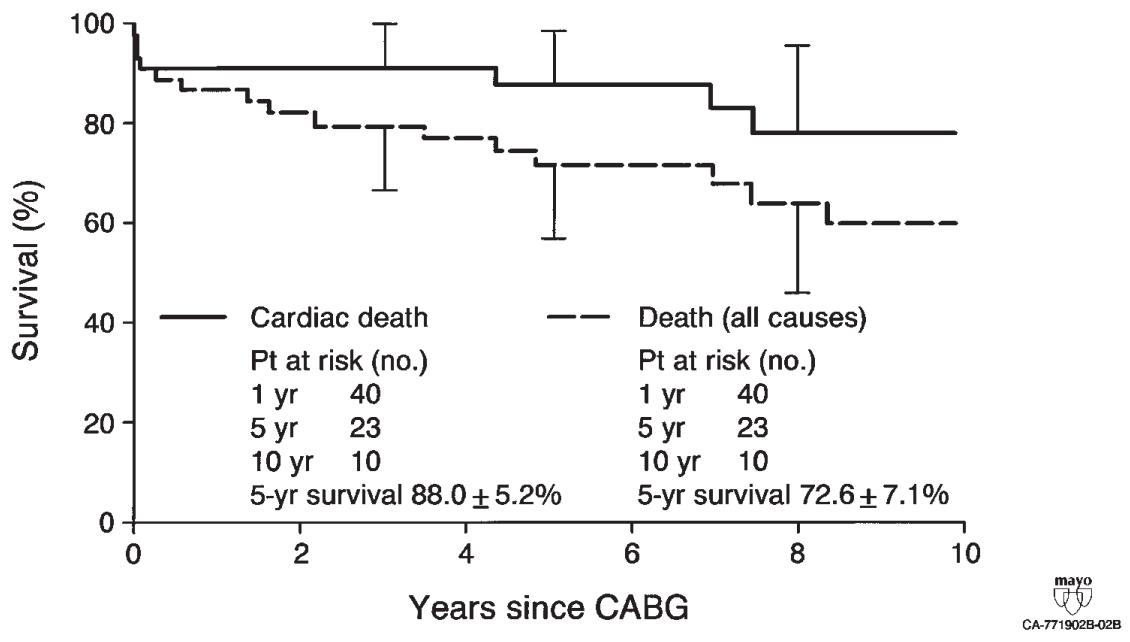

Fig 2. Freedom from cardiac death and death from all causes in 47 patients undergoing coronary artery bypass grafting $(C A B G)$ after mediastinal radiation therapy.

patient, a 59-year-old man with a preoperative ejection fraction of $36 \%$ and an evolving myocardial infarction, had an emergency operation and died on the first postoperative day. The third patient was an 82-year-old woman who died on postoperative day 36 of heart failure after needing prolonged respiratory support and tracheostomy. She had also had a gastrointestinal perforation with abdominal exploration. Four patients, in total, required prolonged ventilatory support ( $>72$ hours). Three patients had a deep sternal wound infection and 1 patient had sternal malunion with no evidence of infection. The LITA was not used in any of the 3 patients with mediastinitis.

Total follow-up was 293.7 patient-years with a mean of $6.2 \pm 5.1$ years. Follow-up New York Heart Association (NYHA) class was I in $51 \%(\mathrm{n}=22)$, II in $26 \%(\mathrm{n}=11)$, III in $14 \%(\mathrm{n}=6)$, and IV in $9 \%(\mathrm{n}=4)$ of patients. Seventeen late deaths occurred. The two major causes of late death were malignancy, either recurrent $(\mathrm{n}=2)$ or new $(\mathrm{n}=5)$, and heart failure $(\mathrm{n}=$ $6)$. Other causes of late death were stroke $(n=1)$, sudden death $(n=1)$, and other noncardiac causes $(n=2)$. Actuarial survivals at 1 year and 5 years were $87.2 \% \pm$ $4.9 \%$ and $72.6 \% \pm 7.1 \%$, respectively (Fig 2). Five patients required 6 late reoperations $(\mathrm{CABG}, \mathrm{n}=3$; aortic valve replacement plus $\mathrm{CABG}, \mathrm{n}=1$; mitral valve repair, $\mathrm{n}=1$; and heart transplantation, $\mathrm{n}=1$ ). Survival free of cardiac-related death, open cardiac reoperation, and redo $\mathrm{CABG}$ at 5 years was $88.0 \% \pm 5.2 \%, 78.3 \% \pm$ $7.3 \%$, and $93.5 \% \pm 4.4 \%$, respectively (Figs 2 and 3 ). Table VI shows a comparison of LITA and saphenous vein usage as an LAD conduit in terms of survival free from death, cardiac death, cardiac reoperation, and CABG reoperation at 3 years. The small numbers of patients prevent any later analysis. The mean interval between the original $\mathrm{CABG}$ and the 6 late cardiac procedures was $4.6 \pm 2.5$ years (2.5-8.6 years).

Follow-up valve assessment by echocardiography was available in only 21 patients $(45 \%)$ with a mean follow-up of $5.9 \pm 4.7$ years. Twelve of these 21 patients were noted to have significant valvular disease (mitral plus tricuspid valve disease, $\mathrm{n}=4$; aortic plus mitral stenosis, $\mathrm{n}=5$; aortic stenosis plus regurgitation, $\mathrm{n}=2$; mild aortic stenosis, $\mathrm{n}=1$ ). Two of these patients required reoperation for this valvular disease. Another 2 of these patients died of congestive heart failure. Six of the 10 patients who were in NYHA class III or IV at follow-up had significant valvular disease.

\section{Discussion}

Over the time frame of this study, an increasing number of patients required $\mathrm{CABG}$ operations after previous mediastinal radiation therapy. Although the number of long-term survivors after radiation therapy for certain malignant neoplasms is increasing, it can be hoped that the frequency of mediastinal complications will diminish with improved radiation therapy techniques. In particular, the use of more frequent but lower dosages of radiation to multiple fields and customized computed tomographic blocking have resulted in more focused and homogeneous dosing of radiation. ${ }^{8,17,18}$ The spectrum of mediastinal radiation injury is broad, extending from minor fibrosis with little or no structural effects to heavy scarring and fusion of mediastinal 


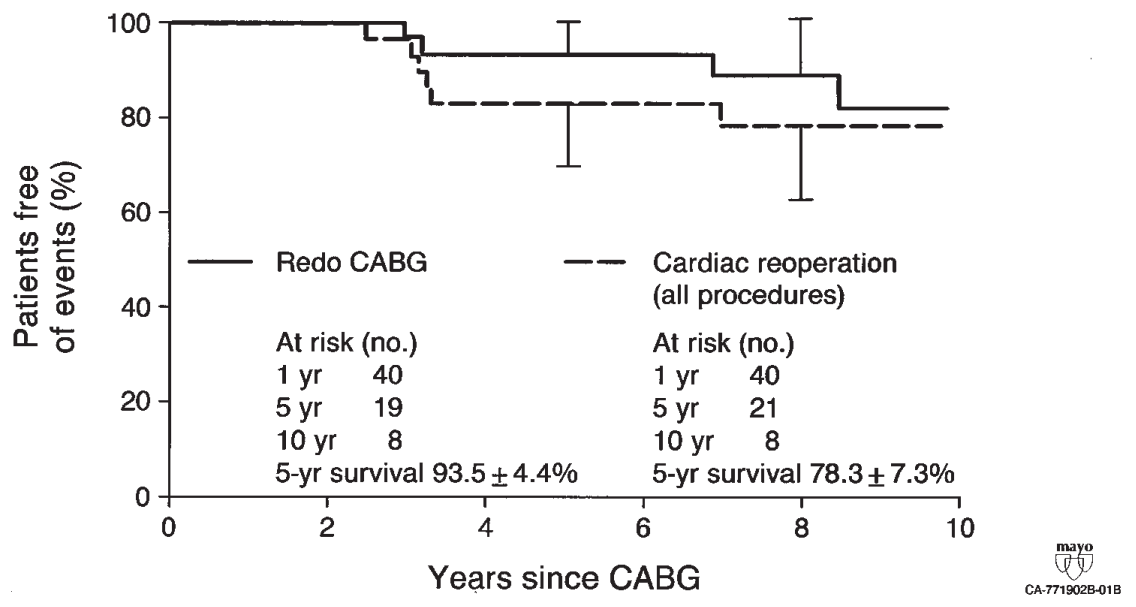

Fig 3. Freedom from redo coronary artery bypass grafting $(C A B G)$ and all cardiac reoperations in 47 patients undergoing $\mathrm{CABG}$ after mediastinal radiation therapy.

Table VI. Comparison of LITA and SV as an LAD graft

\begin{tabular}{lccc}
\hline & \multicolumn{2}{c}{$\begin{array}{c}\text { Survival free from the following } \\
\text { variables at } 3 \text { years }(\%)\end{array}$} & \\
\cline { 2 - 3 } Variable & LITA $(n=14)$ & $S V(n=25)$ & P value \\
\hline Death & $93 \pm 6$ & $76 \pm 9$ & .87 \\
Cardiac death & $100 \pm 0$ & $89 \pm 6$ & .63 \\
Cardiac reoperation & $91 \pm 9$ & $100 \pm 0$ & .27 \\
Redo CABG & $100 \pm 0$ & $100 \pm 0$ & .44 \\
\hline
\end{tabular}

LITA, Left internal thoracic artery; $S V$, saphenous vein; $L A D$, left anterior descending; $C A B G$, coronary artery bypass graft.

structures with extensive pericardial, myocardial, vascular, and valvular damage. ${ }^{8}$ Radiation injury to the aortic arch and great vessels may also occur. ${ }^{19}$ The low incidence of classic risk factors for coronary artery disease in this study, such as hyperlipidemia and a history of smoking, support the role of mediastinal radiation therapy in the development of coronary disease in these patients. Careful preoperative assessment of patients for comorbidities resulting from previous radiation therapy may be helpful in risk assessment for any individual patient. The frequency of carotid stenosis, pulmonary dysfunction, and pericardial constriction indicates the need for preoperative carotid ultrasonography, pulmonary function testing, and echocardiography. ${ }^{19,20}$ Computed tomography of the chest may also be useful in delineating the extent of mediastinal changes. Echocardiography will also yield additional important information on right and left ventricular function, as well as on valvular function. ${ }^{19}$ The frequent presentation of mixed ischemic and valvular heart disease in this patient population mandates careful preoperative echocardiography. This study suggests that valvular disease in this patient population is progressive, so that concomitant valve surgery with CABG should be carefully considered. The progression in valvular heart disease is based on (1) the need for valvular reoperation in 2 patients (neither of whom was in the group of 4 patients with moderate valvular disease at the time of CABG alone); (2) valvular heart disease being implicated in 3 of the 6 late deaths from heart failure and 6 of 10 patients who were in NYHA class II or IV at follow-up; and (3) echocardiographic follow-up. This progression of valvular disease may be underestimated, because echocardiographic follow-up was available in only 21 of the 43 surviving patients, 12 of whom had significant valvular disease. Pathologic assessment of the resected heart valves in 25 of the original 72 patients showed leaflet fibrosis and fibrous shortening of the chordae tendineae in all but 1 mitral valve, consistent with radiation-induced disease. With respect to the aortic valve, one third of valves had diffuse leaflet fibrosis and retraction typical of radiation-induced injury. The other two thirds showed overlapping agerelated degenerative (senile) calcification and varying degrees of fibrosis. Radiation-induced injury appeared to be the main factor for the development of mitral valve disease and at least a contributing factor for the development of aortic valve disease. At this time, we cannot comment on the applicability of valve repair versus replacement, because our analysis of valvular heart disease is not yet complete.

The use of the LITA as an LAD graft in $32 \%$ of patients in this study is similar to the percentage in pre- 
vious studies. ${ }^{11,15}$ The use of the LITA has increased over the time frame of the study to $50 \%$ in the most recent period. The low use of the LITA in the earlier time frames of the study may reflect an era before the full value of the LITA was realized. In addition, the decision not to use the LITA might have been influenced by the concern about a possible increased incidence of mediastinitis after the operation. However, although the incidence of mediastinitis appeared high in this series (3/47), in none of these cases was the LITA used. The increased incidence of mediastinitis is likely due to the low-grade chronic inflammation of radiation therapy compromising local blood supply to the sternum and soft tissues. It is easy to speculate that the LITA surrounded by the mediastinal fibrotic process is likely to be affected by radiation-induced arteritis. This raises the question of long-term patency of these LITA grafts. In the present study, unfortunately, pathologic assessment of LITA grafts is not available. Late occlusion of a LITA graft to the LAD has been reported in a patient who had CABG after mediastinal radiation therapy. ${ }^{21}$ In $20 \%$ of cases in which the saphenous vein was used to bypass the LAD, the surgeon commented on the involvement of the LITA in the mediastinal fibrotic process, obviating its use. Preoperative LITA angiography clearly is desirable but was available in only 1 patient in the study. A normal preoperative angiogram of the LITA would support LITA use in this population. Whether the LITA is the conduit of choice because of its well-known advantages $^{22-25}$ is uncertain in this population, not only because of concerns regarding its involvement by radiation, but also because its positive long-term impact is less in this patient population, who has significant late attrition resulting from neoplasm, valvular heart disease, and heart failure. The comparison of survival free of variables at 3 years between LITA and saphenous vein usage for the LAD conduit (Table VI) and the 5year survival free of redo CABG of $93.5 \%$ (Fig 3) support this contention, at least in the 3- to 5-year time frame. The questionable quality of the LITA graft after mediastinal radiation therapy, the increased risk of mediastinal wound complications, and the reduced impact on 5-year survival raises the legitimate question of whether an alternative arterial graft that is not affected by mediastinal radiation therapy should be used as a bypass conduit for the LAD. The use of the radial artery may be beneficial both for preventing mediastinal wound complications and for avoiding the suboptimal use of the ITA as a conduit. ${ }^{26-28}$

The early result of surgery in this potentially higher risk group of patients is good, with early mortalities of
$8.5 \%$ overall and $6.8 \%$ in the 44 patients with isolated CABG. Although preoperative systolic function was good in the study group, factors present in these patients that might help explain this increased risk include a preponderance of women $(60 \%)$, a high incidence of preoperative left main disease (32\%), pulmonary disease $(32 \%)$, and carotid disease $(23 \%)$, and the increased risk of infection both locally and from residual generalized immune compromise. The deaths reflect these special factors in this population. As well as having an increased early risk, these patients have compromised late survival because of the occurrence of a new cancer, recurrence of the previous cancer, and heart failure, so that 5-year actuarial survival is $72.6 \%$ $\pm 7.1 \%$. Progression of valvular heart disease is a significant factor in the subsequent development of heart failure. Careful follow-up echocardiographic screening may allow intervention to mitigate progression of valvular heart disease.

\section{REFERENCES}

1. Winchester DJ, Menck HR, Winchester DP. The National Cancer Data Base report on the results of a large nonrandomized comparison of breast preservation and modified radical mastectomy. Cancer 1997;80:162-7.

2. Grovas A, Fremgen A, Rauck A, Ruymann FB, Huchinson CL, Winchester DP, et al. The National Cancer Data Base report on patterns of childhood cancers in the United States. Cancer 1997;80:2321-32.

3. van Spronsen DJ, Dijkema IM, Vrints LW, Hofstra G, Crommelin MA, Erdkamp FL, et al. Improved survival of Hodgkin's patients in south-east Netherlands since 1972. Eur J Cancer 1997;33:436-41.

4. Rosenberg SA. The continuing challenge of Hodgkin's disease. Ann Oncol 1991;2:29-31.

5. Lederman GS, Sheldon TA, Chaffey JT, Herman TS, Gelman RS, Coleman CN. Cardiac disease after mediastinal irradiation for seminoma. Cancer 1987:60:772-6.

6. Strender LE, Lindahl J, Larsson LE. Incidence of heart disease and functional significance of changes in the electrocardiogram 10 years after radiotherapy for breast cancer. Cancer 1986;57: 929-34.

7. Boivin JF, Hutchison GB, Lubin JH, Mauch P. Coronary artery disease mortality in patients treated for Hodgkin's disease. Cancer 1992;69:1241-7.

8. Hancock SL, Tucker MA, Hoppe RT. Factors affecting late mortality from heart disease after treatment of Hodgkin's disease. JAMA 1993;270:1949-55.

9. Benoff LJ, Schweitzer P. Radiation therapy-induced cardiac injury. Am Heart J 1995;129:1193-6.

10. Annest LS, Anderson RP, Li W, Hafermann MD. Coronary artery disease following mediastinal radiation therapy. J Thorac Cardiovasc Surg 1983;85:257-63.

11. Hicks GL Jr. Coronary artery operation in radiation-associated atherosclerosis: long-term follow-up. Ann Thorac Surg 1992;53: 670-4.

12. Gharagozloo F, Clements IP, Mullany CJ. Use of the internal mammary artery for myocardial revascularization in a patient 
with radiation-induced coronary artery disease. Mayo Clin Proc 1992;67:1081-4.

13. Reber D, Birnbaum DE, Tollenaere P. Heart diseases following mediastinal irradiation: surgical management. Eur J Cardiothorac Surg 1995;9:202-5.

14. Veeragandham RS, Goldin MD. Surgical management of radiation-induced heart disease. Ann Thorac Surg 1998;65:1014-9.

15. Kleikamp G, Schnepper U, Korfer R. Coronary artery and aortic valve disease as a long-term sequel of mediastinal and thoracic irradiation. Thorac Cardiovasc Surg 1997;45:27-31.

16. Stewart JR, Fajardo LF, Gillette SM, Constine LS. Radiation injury to the heart. Int J Radiat Oncol Biol Phys 1995;31:1205-11.

17. Rosenberg SA. Reducing the toxicity of the combined modality therapy of favorable stage Hodgkin's disease. Eur J Cancer 1992; 28A: $1379-80$.

18. King V, Constine LS, Clark D, Schwartz RG, Muhs AG, Henzler $\mathrm{M}$, et al. Symptomatic coronary artery disease after mantle irradiation for Hodgkin's disease. Int J Radiat Oncol Biol Phys 1996; 36:881-9.

19. Andros G, Schneider PA, Harris RW, Dulawa LB, Oblath RW, Salles-Cunha SX. Management of arterial occlusive disease following radiation therapy. Cardiovasc Surg 1996;4:135-42.

20. Lund HB, Ihlen H, Voss BM, Abrahamsen AF, Nome O, Kongerud J, et al. Increased risk of heart valve regurgitation after mediastinal radiation for Hodgkin's disease: an echocardiographic study. Heart 1996;75:591-5.

21. Schulman HE, Korr KS, Myers TJ. Left internal thoracic artery graft occlusion following mediastinal radiation therapy. Chest 1994; 105:1881-2.

22. Cameron A, Davis KB, Green G, Schaff HV. Coronary bypass surgery with internal-thoracic-artery grafts-effects on survival over a 15-year period. N Engl J Med 1996;334:216-9.

23. Lytle BW, Loop FD, Cosgrove DM, Ratliff NB, Easley K, Taylor PC. Long-term (5 to 12 years) serial studies of internal mammary artery and saphenous vein coronary bypass grafts. J Thorac Cardiovasc Surg 1985;89:248-58.

24. Loop FD, Lytle BW, Cosgrove DM, Stewart RW, Goormastic M, Williams GW, et al. Influence of the internal-mammary-artery graft on 10-year survival and other cardiac events. N Engl J Med 1986;314:1-6.

25. Sargeant P, Lasaffre E, Flameng W, Suy R. Internal mammary artery: methods of use and their effect on survival after coronary bypass surgery. Eur J Cardiothorac Surg 1990;4:72-8.

26. Acar C, Jebara VA, Portoghese M, Beyssen B, Pagny JY, Grare P, et al. Revival of the radial artery for coronary artery bypass grafting. Ann Thorac Surg 1992;54:652-60.

27. Brodman RF, Frame R, Camacho M, Hu E, Chen A, Hollinger I. Routine use of unilateral and bilateral radial arteries for coronary artery bypass graft surgery. J Am Coll Cardiol 1996;28:959-63.

28. da Costa FDA, da Costa IA, Poffo R, Abuchaim D, Gaspar R, Garcia L, et al. Myocardial revascularization with the radial artery: a clinical and angiographic study. Ann Thorac Surg 1996; 62:475-80

\section{Discussion}

Dr Bruce W. Lytle (Cleveland, Ohio). This is an important paper because it highlights radiation-induced heart disease, which in my judgment is one of the most difficult pathologic entities that we deal with. Mediastinal radiation causes numerous problems. Patients with radiation-induced heart disease may have coronary artery disease or pericardial constriction. Most have some type of a restrictive cardiomyopathy with diastolic dysfunction, sometimes in the face of reasonable systolic function. They can have aortic calcification or calcification of the fibrous skeleton of the heart, causing aortic stenosis and insufficiency, mitral stenosis and insufficiency, and tricuspid insufficiency. Cerebrovascular disease is also prevalent, as well as carotid artery stenosis and pulmonary fibrosis.

The authors have focused on a group with a milder form of radiation-induced heart disease-patients with isolated coronary artery disease without valvular heart disease. Despite that, this is a high-risk group, with $8.5 \%$ of the patients dying. Of the 40 patients who survived, 17 died late, and of the late survivors, 10 had class III or class IV symptoms. Furthermore, more than half of the patients who were studied late had significant valvular heart disease.

The cardiac injury and mediastinal fibrosis caused by radiation is progressive. Once a patient has a primary operation, things get worse before reoperation. If the primary operation is difficult, reoperations can be an absolute nightmare once aortic calcification and severe valvular heart disease have developed. Therefore primary operations for patients with mediastinal radiation therapy should be very carefully considered. Obviously, they were in this series, inasmuch as the patients virtually all had class III or class IV symptoms and had a high incidence of left main disease. If there are strong indications for surgery, a careful preoperative work-up is needed to define the associated conditions, and moderate valvular lesions need to be treated during the first operation.

I have 2 questions. You excluded the patients with valvular heart disease from your analysis, but do you have any feeling about the incremental risk that valvular heart disease carried with it at the time of those primary operations?

The second question is a bookkeeping one. The manuscript lists 40 hospital survivors and 17 late deaths, but the late functional class data were listed as applying to 39 patients. How did that all add up?

Dr Handa. Thank you, Dr Lytle, for your comment. We currently are evaluating in more detail those patients with valvular heart disease complicating mediastinal radiation therapy. Definitive comments today would be premature. However, 3 patients with moderate mitral valve regurgitation before the operation and 1 patient with moderate tricuspid regurgitation who had isolated CABG surgery did not have valvular lesions at follow-up.

To clarify the numbers: There were 47 patients in this study, 4 of whom died, leaving 43 survivors. Among these 43 patients, at a mean follow-up of $6.2 \pm 5.1$ years, NYHA class was I in $51 \%(\mathrm{n}=22)$, II in $26 \%(\mathrm{n}=11)$, III in $14 \%(\mathrm{n}=6)$, and IV in $9 \%(\mathrm{n}=4)$.

Dr Hillel Laks (Los Angeles, Calif). I think there are too few papers addressing this very difficult problem. One of the challenges that we face in a transplant program is the evaluations of patients such as these, who have poor ventricular 
function, for either CABG or valvular surgery. In general, in those patients with very low ejection fractions, there seems also to be a severe diastolic dysfunction of the heart, so that these patients do not seem to do well with these more conventional types of surgery. In this experience, how many of the patients had ejection fractions in the $20 \%$ or $30 \%$ range and what were the outcomes in that group of patients?

Dr Handa. We agree that diastolic dysfunction is a valid issue that is difficult to quantitate in these patients. The mean ejection fraction in this series was $55 \%$. In the overall series of 47 patients, preoperative ejection fraction was available in 35 . Of these 35 patients, 24 had an ejection fraction greater than $50 \%, 6$ had an ejection fraction of $40 \%$ to $50 \%, 4$ had an ejection fraction of $30 \%$ to $40 \%$, and 1 patient had an ejection fraction of $26 \%$.

Dr Laks. In patients with radiation disease of the posterior part of the heart and a very low ejection fraction, our bias would be toward transplantation rather than other forms of surgery in terms of the short- and long-term outcome. Would you agree with that?

Dr Handa. We agree completely with your comments. Four of our patients with end-stage radiation-induced cardiac disease have undergone transplantation. In 3 of these patients the echocardiographic ejection fractions were $15 \%$ and in the fourth, $20 \%$. All patients have done well at a current mean follow-up of 3 years.

\section{Online-www.aats.org}

Now you can get The Journal of Thoracic and Cardiovascular Surgery online. The Journal online brings you faster delivery time, easy searching of current and back issues, links to PubMed, AATS, WTSA and other important sites, and more. Visit the Journal online today. 